\title{
dossier
}

\section{Misión en cuestión: antropología y evangelización en la Prelatura de Ayaviri (1968-1975)}

\author{
Noah OeHri \\ Universität Bern (Berna, Suiza) \\ noah.oehri@hist.unibe.ch
}

Código ORCID: 0000-0002-3084-7240

\section{RESUMEN}

Una nueva aproximación hacia la religiosidad popular $-\mathrm{y}$ su valoración- marcó significativamente la actuación de la Iglesia católica latinoamericana en las décadas posconciliares y dio lugar a un creciente número de investigaciones antropológicas de las subculturas religiosas. No obstante, las reformas de las prácticas evangelizadoras en línea con dichos estudios despertaron poco interés académico. Este artículo analiza la compleja relación entre antropología y misión en la Prelatura de Ayaviri (Puno), que a partir de la Conferencia Episcopal de Medellín (1968) se apoyó en la investigación científico-social 
para reformular su práctica pastoral. Específicamente, este artículo aclara cómo el renovado compromiso de la prelatura con el «otro», el campesino quechua, no solo contribuyó a la producción de conocimientos sobre el panorama sociorreligioso regional, sino también causó dificultades a una Iglesia cuya naturaleza misionera fue objeto de escrutinio y cambio a principios de los años setenta.

Palabras clave: antropología religiosa, misión, Iglesia católica, Perú

\section{Mission in Question - Anthropology and Evangelization in the Prela- ture of Ayaviri (1968 - 1975)}

\section{Abstract}

A new approach to — and appreciation of - popular religiosity significantly marked the Latin American Catholic Church in the post-conciliar decades and gave rise to a growing number of anthropological investigations of religious subcultures. However, the reforms of evangelizing practices in response to these studies have thus far aroused little academic interest. This article analyzes the complex relationship between anthropology and mission in the Prelature of Ayaviri (Puno), which, beginning with the Episcopal Conference of Medellín (1968), relied on social-scientific research to reformulate its pastoral practice. Specifically, this article elucidates how the prelature's renewed engagement with the «other», the Quechua peasant, not only contributed to the knowledge production on the regional socio-religious panorama, but also caused difficulties for a church whose missionary nature was subject to scrutiny and change during the early 1970s.

KeYwords: religious anthropology, mission, Catholic Church, Peru 
A los misioneros del Ande, el Concilio y el mundo indígena, lanzan el mismo reto: ¿Tendremos la verdadera caridad, la imaginación, el espiritu de creatividad necesarios para volver a escribir nuestros catecismos, nuestros sermonarios, nuestra espiritualidad, nuestra teología en el contexto de la Pachamama, de los Apus, de las estrellas? Luis Dalle, «El Despacho»

Good missionaries have always been good anthropologists. Eugene A. Nida, Culture and Customs

En MARZO de 1969 Edmond GaUthier, un sacerdote francés Fidei Donum, publicó un artículo en la revista misionera Parole et Mission criticando el trabajo realizado por el clero extranjero en la Prelatura de Ayaviri, ${ }^{1}$ ubicada en el norte del departamento de Puno. En su opinión, el enfoque del trabajo social, con el que la mayoría de los sacerdotes estaban comprometidos hasta ahora, hizo que la Iglesia pareciera como una organización de caridad cuya misión terminó por fomentar relaciones paternalistas con sus discípulos. Caracterizando esta acción benéfica como una «ilusión», Gauthier criticó la práctica de recaudar fondos del extranjero para proyectos de desarrollo cuyo éxito e impacto era a menudo cuestionable. Como «gringos entre los indios», argumenta, los misioneros tuvieron que replantearse su práctica pastoral entre aquellas «almas misteriosas» que todavía parecían inalcanzables por «su cultura, su lengua y sus creencias milenarias». Traducir el Evangelio y adaptarlo a la «psicología profunda del indio», sin embargo, requería una presencia a largo plazo de misioneros o, en el mejor de los casos, su sustitución

1 Dado que la Prelatura de Ayaviri se encontraba, desde su creación en 1959, bajo administración y responsabilidad de la Congregación de los Sagrados Corazones, la mayoría del clero era conformado por misioneros franceses de dicha congregación. 
por sacerdotes indígenas (P. M. 1969: 54-55, 58). Publicada bajo un seudónimo, la crítica de Gauthier causó controversia entre el clero de la prelatura, ${ }^{2}$ pero también reflejaba un debate emergente sobre la nueva aproximación y comprensión de la práctica religiosa en los Andes sureños del Perú.

A finales de 1968 Luis Dalle, director del recién fundado Instituto de Pastoral Andina (IPA), asistió a una ofrenda a la Pachamama en una hacienda en las afueras de Ayaviri. Poniendo atención a los detalles, Dalle nos resume su experiencia durante esa noche de noviembre en la que pasó observando un rito del cual no tenía conocimiento previo. Su testimonio impreso de la ceremonia revela su interés personal en conocer las prácticas religiosas del sur de los Andes. Reflexionando sobre su asistencia, Dalle planteó preguntas, citadas en el epígrafe de este texto, sobre los paralelismos entre el catolicismo y la inserción de los agentes pastorales en el entorno sociorreligioso regional. De acuerdo con Gauthier, formula una crítica basada en la implementación de prácticas de desarrollo que «sigue[n] atropellando al alma indígena», en vista de que la población no fue involucrada ni consultada para la introducción de «proyectos, iniciativas, programas, materiales» que provinieran de actores religiosos y laicos. En otras palabras, el suministro de ayuda al desarrollo fomentaba el paternalismo y marcaba la alteridad del campesinado andino. Una nueva orientación pastoral, en su opinión, debía comprender los «valores más profundos» de la población quechua y, al hacerlo, «devolver la confianza en sí mismo» (Dalle 1969: 154).

2 Bajo la dirección del Vicario General, se envió una carta de queja a Parole et Mission impugnando las observaciones de Gauthier y rechazando su crítica por injustificada, ya que se basaba en la falta de experiencia a largo plazo. AHPA, Caja Párrocos Antiguos, Edmond Gauthier, carta de A. M. Henry a Jean Inizan y a los padres franceses de la prelatura, 24 marzo de 1969; y carta de Edmond Gauthier a Luciano Metzinger, 28 de marzo de 1969. 
Una nueva comprensión de la identidad sociorreligiosa del otro «misterioso», sin embargo, requería el estudio científico de su práctica religiosa. La creación del IPA como una institución de investigación, para sacerdotes y actores laicos de la región sur de los Andes, reflejó los debates en curso sobre la reforma y adaptación de la práctica pastoral a mediados de la década de 1960. Ad Gentes y Gaudium et Spes, la «constitución pastoral» del Vaticano II, ya pedían una aproximación a la cultura local a través de la producción de conocimientos sobre lenguas, ritos y expresiones folclóricas y su adaptación a las mismas (Piedra Valdez 2013: 21-24). En la misma línea, la reunión del Consejo Episcopal Latinoamericano (CELAM) de abril de 1968, en Melgar (Colombia), cuestionó la naturaleza de la práctica pastoral en el territorio misionero, a menudo no adaptada —o simplemente ajena — a la realidad sociorreligiosa (Departamento de Misiones 1969). El mismo año, los obispos latinoamericanos reunidos en Medellín promovieron la realización de «estudios serios y sistemáticos sobre la religión popular en todas sus manifestaciones»(VI Pastoral Popular, 10). Estos debates en torno a la actividad misionera hicieron eco de las críticas expresadas por Gauthier y Dalle, poniendo en tela de juicio la posicionalidad y el modus operandi de los agentes religiosos y laicos que, en muchos casos, habían manifestado una falta de conocimiento y aprecio por aquellos a quienes buscaban atender y cuidar (espiritualmente).

Dada su creciente preocupación por comprender el «misterio» de la religiosidad andina, la Prelatura de Ayaviri tomó, según Alejandro Estenós Loayza y Manuel Ugarte Cornejo, una orientación «indigenista-cultural» a principios de los años setenta (2009: 30). Tres antropólogos trataron de proporcionar nuevos conocimientos sobre la práctica religiosa —llamada religiosidad «andina», «quechua» o «india»—3 al mismo tiempo que apoyaron a la Iglesia en su

3 Con la reforma agraria (1969) se inicia un cambio terminológico en el Perú, privilegiando el término «campesino» sobre «indígena». En este artículo uso ambas 
misión de adaptar su práctica pastoral al ambiente sociorreligioso del norte de Puno. Thomas Garr (1972) estudió la relación entre el catolicismo y la religión quechua en las parroquias de Coaza, Orurillo y San Juan del Oro, mientras que Manuel Marzal (1988) analizó las prácticas y creencias religiosas en la misma ciudad de Ayaviri. Al mismo tiempo, el exmisionero Jean Berthelot terminó sus estudios de antropología con una tesis (1972) sobre religión y desarrollo en la provincia de Carabaya basada en su experiencia de párroco en Coaza. Los tres estudios tenían como objetivo comprender la práctica religiosa en un contexto en el que los esfuerzos de los misioneros por evangelizar la población parecían, a pesar de cuatro siglos de presencia católica, poco fructíferos. En base a los resultados obtenidos y a un nuevo surgimiento de comprensión de la misión aparecen nuevos desafíos para la orientación pastoral en la prelatura, que merecen ser discutidos y planteados: ¿hasta qué punto los estudios antropológicos dieron un nuevo impulso a la Iglesia en su proceso de reforma en curso de la práctica pastoral? O, retomando la terminología de Gauthier, ¿cómo contribuyeron y se beneficiaron los sacerdotes «gringos» de la aproximación científica hacia las «almas misteriosas» de los Andes?

Centrándose en las interrelaciones entre los esfuerzos de evangelización y la antropología religiosa, este artículo analiza la producción y el uso de los estudios antropológicos en el trabajo pastoral de la Prelatura de Ayaviri. Al hacerlo, se propone contrastar las ideas e ideales de la misión y el trabajo pastoral con las enseñanzas del Vaticano II y el proceso de reforma eclesial en el Perú, coincidiendo con el reformismo político de Velasco Alvarado (1968-1975). ${ }^{4}$ En

palabras de manera sinónima, intentando reflectar el uso de la terminología en las fuentes consultadas. Sobre la complejidad de la terminología de etnicidad y clase en el Perú de la década de 1970, ver Salomon (1982).

4 Sobre las a menudo armoniosas, pero a veces tensas relaciones entre la Iglesia y el Estado durante este período, ver Klaiber (1992: 276-299), Romero (1982: 128-134) y Young-Hyun (2005). 
particular, se trata de comprender cómo la nueva orientación apostólica no solo impulsó nuevos estudios sobre la práctica sociorreligiosa regional (Piedra Valdez 2103), sino cómo este proceso desafió el celo misionero de una Iglesia cuya práctica pastoral fue sometida a escrutinio y reformas durante la década de 1970. A partir de un análisis de los estudios de Berthelot, Garr y Marzal, así como de fuentes procedentes de los archivos eclesiásticos, ${ }^{5}$ se sostiene que el trabajo de los antropólogos y del clero proyectaba un nuevo ideal de trabajo misionero cuya realización, sin embargo, se enfrentaba a importantes obstáculos personales y contradicciones ideológicas. Es importante recordar, a este respecto, que los relatos y las perspectivas que se examinan reflejan la posición de los antropólogos y misioneros que todavía se esfuerzan por comprender y, en última instancia, evangelizar a estas «almas misteriosas».

Dividido en tres partes, este artículo abordará respectivamente (1) las interrelaciones de la antropología y la evangelización en el contexto latinoamericano y surandino; (2) los estudios realizados en la Prelatura de Ayaviri durante la primera mitad de los años setenta; (3) la recepción de dichos estudios y sus implicaciones para la reforma pastoral. Combinando el análisis histórico de la práctica pastoral con una discusión crítica de los estudios antropológicos, este artículo busca finalmente contribuir a la comprensión de las interdependencias entre antropología y evangelización en el trabajo misionero de la segunda mitad del siglo XX. O, reformulando el epígrafe, pretendo entender hasta qué punto los antropólogos, a través de su contribución a la reforma pastoral, también contribuyen a promover «mejores misioneros».

5 El análisis se basa principalmente en el Archivo Histórico de la Prelatura de Ayaviri, pero también utiliza fuentes encontradas en los Archivos de la Congregación de los Sagrados Corazones en Lima (Provincia Andina-Zona Perú) y Montgeron (Francia), así como del Archivo del Obispado de Puno. 


\section{EL «GIRO ANTROPOLÓGICO» EN LA OBRA MISIONERA}

En abril de 1968, el departamento de misiones del CELAM organizó un encuentro en Melgar, Colombia, para evaluar la actividad pastoral, discutir y elaborar nuevas orientaciones que respondan a las demandas y necesidades de los territorios de misión. ${ }^{6} \mathrm{Al}$ tratar estos temas, los participantes — entre otros, Luciano Metzinger, prelado de Ayaviri, y Gustavo Gutiérrez - analizaron en primer lugar el significado contemporáneo de «territorios de misión», es decir, el espacio donde se requerían esfuerzos de evangelización. En el documento de base, La realidad de las misiones en América Latina, se han esbozado varias perspectivas sobre la noción de misión y sus manifestaciones territoriales. Mientras bajo el derecho canónico solo aquellas jurisdicciones que dependen de Propaganda Fide son oficialmente consideradas territorios de misión, el documento de base sugiere que la mayoría de las setenta y cinco prelaturas existentes en todo el continente deberían ser consideradas misiones. El autor José Manuel Román argumenta que el clero en ambos tipos de jurisdicciones, así como en algunas diócesis, se enfrenta a un «problema antropológico» - la presencia significativa de poblaciones indígenas o afrodescendientes consideradas insuficientemente evangelizadas - así como a la falta de desarrollo socioeconómico, sobre todo en el campo de la educación. La actividad pastoral en estos territorios de misión se consideró particularmente difícil debido a la persistencia del pluralismo religioso, a una participación a menudo indiferente en las misas y a la falta de obediencia a los códigos morales católicos. Las pequeñas prelaturas, a menudo de reciente creación y consideradas «huérfanas», no contaban con el apoyo de las instituciones misioneras romanas ni de los episcopados

6 La reunión de Melgar siguió a la primera reunión del Departamento de Misiones del CELAM que se celebró en Ambato, Ecuador, el año anterior. La primera tenía por objeto dotar al departamento de los instrumentos necesarios para el estudio de la práctica misionera (Scatena 2007: 267). 
nacionales en lo que se refiere a la provisión de recursos personales y materiales (Román 1969: 191-212). Como lo ejemplifica el caso de Ayaviri, esta situación avivó aún más la dependencia de estas jurisdicciones de las congregaciones religiosas (extranjeras), cuyo personal y capital tuvieron que ser movilizados en gran medida para sostener la misión en estos territorios.

Un estudio sociológico del trabajo de los misioneros en el subcontinente, que abarcó a todo el personal religioso que trabajaba en cada territorio de misión, así como a sus superiores al frente de las diócesis, prelaturas y vicariatos, puso de manifiesto la complejidad de las experiencias misioneras contemporáneas (de Recasens 1969: 65-125). Los resultados del estudio delataron el «problema antropológico» en las diferentes jurisdicciones de misión. Entre otros aspectos, la encuesta destacó en primer lugar la falta de preparación del personal religioso, seguido de una gran mayoría trabajando «al margen de todo análisis de la cultura nativa», así como la falta de interés de los misioneros por las estructuras económicas y sociales locales y por «el gran contexto mágico-religioso primitivo» (de Recasens 1969: 89-90). De hecho, el 56 \% de los participantes en el estudio opinaron que las personas con las que trabajan son solo «superficialmente católicas», lo que pone de relieve la necesidad de evangelización, pero también insinuó que los esfuerzos de las misiones anteriores no habían tenido éxito. El antropólogo José de Recasens atribuyó la falta de cambio en cuatro siglos y medio de evangelización al hecho de que la actividad misionera solo afecta a una parte del organismo social:

A menos que los misioneros conozcan total y absolutamente los detalles de los sistemas de vida nativos, las pautas de conducta, los patrones de pensamientos, las ideas y valores propios de la otra cultura y más aún, la estructura dinámica y la función que cumplen para esas otras gentes, la tarea de una dirección espiritual no podrá ser llevada a cabo con eficacia. ${ }^{?}$

$7 \quad$ De Recasens (1969: 173). 
En otras palabras, los misioneros solo pueden superar los fracasos del pasado con la ayuda de un conocimiento más amplio del entorno en el que realizan su trabajo. La antropología, desde este punto de vista, se convierte en una herramienta indispensable para el misionero en su trabajo como agente de cambio (religioso). O en palabras de otro colaborador, Luis R. González, «toda pastoral, y en particular la misionera, sin dejar de ser profundamente teológica, debe ser necesariamente antropológica» (González 1969: 173).

Más allá del «problema antropológico», aspectos importantes de la dialéctica de la presencia católica, especialmente en lo que se refiere a la acogida de los misioneros, fueron fijados al interés científico. Los estudios sociológicos encargados por el Centro Intercultural de Documentación (CIDOC) de Ivan Illich, famoso crítico de la obra misionera estadounidense (1967), por ejemplo, cuestionaron estas concepciones unidireccionales del cambio cultural. Más bien ilustra cómo la presencia de los misioneros llevó a un cambio en la percepción de la Iglesia católica. Los estudios sobre las prelaturas de Juli y Sicuani, ${ }^{8}$ por ejemplo, analizan los puntos de vista locales sobre los misioneros extranjeros en cuanto al tamaño de sus casas, la cantidad de coches y dinero a su disposición, así como el trabajo pastoral realizado en los Andes sureños. Según las encuestas del CIDOC, el papel del misionero como agente de cambio dependía de su compromiso con sus feligreses y variaba mucho dependiendo de su educación, género y riqueza. Aunque los participantes en la encuesta tenían una opinión generalmente positiva sobre la presencia misionera, los encuestados también criticaban a algunos misioneros por usar ropa civil, los consideraban agentes del imperialismo nor-

8 Ambas encuestas sobre el ambiente sociorreligioso en las prelaturas de Juli y Sicuani, creadas como Ayaviri a finales de los años 1950, se realizaron en 1968 con el fin de conocer las opiniones y perspectivas del clero y de los religiosos con respecto a la presencia misionera, siendo las prelaturas administradas respectivamente por las órdenes Maryknoll y Carmelitas americanas durante la última década. 
teamericano (Ponce G. et al. 1970: cuadros 107 y 112) o los acusaban de «aprovecharse de la ignorancia de la gente» (Negre Rigol et al. 1970: cuadro 103). Concluyendo las encuestas, los investigadores argumentan que los resentimientos mutuos entre los misioneros y la población andina se remontan a «diferencias culturales», que dieron forma a sus respectivos encuentros y, en su opinión, continuaron inhibiendo cualquier otro acercamiento entre el clero y los feligreses, así como una mejor comprensión recíproca de los mismos (Ponce G. et al. 1970; Negre Rigol et al. 1970).

La preocupación por las diferencias culturales resonó entre los clérigos en los Andes meridionales hacia finales de la década de 1960. Los encuentros regionales para la coordinación del trabajo pastoral entre las diócesis y las prelaturas se multiplicaron a medida que las jerarquías eclesiásticas buscaban respuestas comunes a los problemas crecientes en la vocación, la educación catequística y la práctica de evangelización. El Seminario Menor San Martín de Porres de Puno, por ejemplo, experimentó una disminución continua del número de estudiantes, junto con dificultades financieras que llevaron a su cierre a finales de 1968. Después de más de veinticinco años de esfuerzos para promover la vocación local, primero encabezado por los misioneros Maryknoll (Fitzpatrick-Behrens 2012) y luego llevado por las tres jurisdicciones puneñas, solo doce sacerdotes habían completado sus estudios en el seminario. Muchos de ellos, «habiéndose acostumbrado a una vida bien protegida y divorciada de la realidad de su ambiente, encuentran un gran choque el vivir en un pueblo quieto y pobre»y, por lo tanto, estaban insatisfechos con su profesión. La falta de interés, así como la floreciente «mentalidad burguesa» de los seminaristas, no solo socavó los esfuerzos por promover la vocación, sino que, al igual que la crítica al desarrollismo paternalista mencionada en la introducción, cuestionó la orientación apostólica de la Iglesia en Puno. ${ }^{9}$

9 AHPA, Caja Reunión Obispos Puno, Clausura del Seminario Menor San Martín de Porras, 3 de octubre de 1968. 
A partir de febrero de 1968, los obispos de los Andes sureños discutieron la posibilidad de promover la investigación pastoral para ayudar a mejorar y reorientar el trabajo apostólico en los diferentes niveles de gobierno eclesial. Un nuevo centro de investigación pastoral debería proporcionar educación «para el mejor entendimiento del campesino y sus necesidades» a los sacerdotes y laicos trabajando en la zona. ${ }^{10} \mathrm{Al}$ apoyar la realización de un curso regional de un mes de duración sobre educación pastoral, que se llevaría a cabo por primera vez en septiembre de 1968 en el Seminario del Cusco, los obispos reconocieron que el trabajo pastoral anterior en muchos casos resultó ser ineficaz y necesitaba una adaptación al entorno en el que los sacerdotes estaban llevando a cabo su misión. En otros términos, buscaron una respuesta regional al «problema antropológico» existente en sus respectivas jurisdicciones.

El IPA, como principal iniciativa regional para la reforma pastoral, buscó mejorar la atención pastoral en los departamentos de Apurímac, Cusco y Puno y, de acuerdo con las enseñanzas de la reforma eclesial, adaptar el trabajo apostólico al medio geográfico de la llamada «Iglesia del Sur Andino» (Klaiber 1992: 322-325). Como «expresión de la inquietud pastoral existente», el Instituto además pretendía contribuir a la creación de una «pastoral de conjunto». ${ }^{11}$ El primer cursillo ofrecido por el IPA incluyó cursos de etnología, antropología aplicada y antropología religiosa, enfatizando la necesidad de superar los principales obstáculos que enfrentan los misioneros de los Andes:

No es exageración afirmar que el alma del indio es un misterio para quienes son extraños a su medio. No solo por su tradicional mutismo, sino por la gran diferencia de psicología, de visión de las cosas y el retraso cultural de siglos. Estos factores actúan como barreras que

10 AHPA, Caja Reunión Obispos Puno, Reunión Interregional de los Obispos del Altiplano, Ayaviri, 14-15 de febrero de 1968.

11 AHPA, Caja IPA, DSC05563. 
impiden conocer al indio con profundidad, apreciar sus valores y las posibilidades para la fe. Se puede hablar de un desconocimiento, mayor aún, cuando se intenta describir su mundo religioso. La coexistencia de ritos, de creencias, de manifestaciones de fe, en que se mezcla lo cristiano con lo pagano, da pie a interpretaciones equivocadas sobre su religiosidad. Establecer la pastoral sobre estas vagas apreciaciones es un riesgo si se quiere conducir al indio hacia una fe personalmente vivida, y hacia una Iglesia renovada. ${ }^{12}$

Estos cursos tenían como objetivo acceder a una nueva comprensión de la población campesina, con un enfoque más humanista en su práctica religiosa, permitiendo así superar las barreras que previamente habían impedido a los misioneros comprender a sus feligreses. De acuerdo con una encuesta, la mayoría de los participantes de hecho atendieron al curso por el «deseo de comprender el indígena y poder ayudarlo». ${ }^{13} \mathrm{Al}$ construir discursivamente el «alma misteriosa» como una encarnación de lo desconocido, que está físicamente cerca pero mentalmente fuera de su alcance, la práctica religiosa se convirtió en objeto de escrutinio y fascinación para todos aquellos que pretendían adaptarse y (re)negociar su celo misionero. José Luis González, un misionero español, por ejemplo, recuerda las largas conversaciones con Luis Dalle después de su asistencia a una ofrenda nocturna a la Pachamama. A pesar de su experiencia de trabajo en la sierra andina, tanto Dalle como González sintieron que esta experiencia — considerada tanto «confusa» como «fascinante»— tenía ramificaciones para su acción pastoral. Escribe González: «Despertábamos a una realidad que, no obstante su cercanía, nos había pasado inadvertida» (1982: 20).

12 AHPA, Caja IPA, «IPA: Programa de Estudios», s/f.

13 AHPA, Caja IPA, «Conclusiones del Estudio de Opinión en el Cursillo del IPA», Cusco, 20-26 de septiembre de 1968. 
Mediante la publicación de la revista Allpanchis $^{14}$ y de su boletín, el IPA proporcionó dos plataformas que, sobre todo durante los años iniciales, estimularon el intercambio científico y el debate de nuevas perspectivas sobra la dialéctica del catolicismo y las creencias andinas. Pacífico Zegarra, sacerdote cusqueño, argumentó en mayo de 1969 que la Iglesia católica en el Sur Andino no solo requería una práctica pastoral vernácula, sino una andina, desarrollada para los hombres y mujeres de la sierra. «Un idioma, unas costumbres, unos signos de expresión tan propios y diferentes a los importados», afirmó, «reclaman una acción pastoral completamente diferente» (1969: 1). El antropólogo jesuita Manuel Marzal, entonces responsable de los cursos de antropología religiosa, advirtió que «el campesino de los Andes pertenece a otra cultura y a otra época que el sacerdote» (1970: 6). Estas preocupaciones marcaron los debates en el Instituto, ya que se convirtió en un nexo para la coordinación de actividades que buscaban identificar y superar los desafíos de la nueva realidad pastoral de los Andes del Sur. De acuerdo con las discusiones y el debate en torno a la contribución de la antropología a la práctica misionera, el IPA buscó ante todo «ayudar a los sacerdotes, a las religiosas y a los laicos en general a convertirse en mejores agentes pastorales» antes de intentar hacer de los campesinos mejores cristianos (Klaiber 1992: 323).

Para entender dichas reformas pastorales, que no fueron homogéneas ni simultáneas entre Juli y Abancay, la siguiente parte se focaliza en el estudio del caso de la Prelatura de Ayaviri como un lugar donde la presencia simultánea de misioneros extranjeros y antropólogos condujo a un debate sobre el papel y la posición del clero frente a la realidad religiosa andina.

14 Según el director Juan Hugues (1973: 3-4), «el fin principal de Allpanchis es proporcionar un material de reflexión a los agentes pastorales para que revisen su acción y aprendan a estimar la cultura del pueblo con quien comparten su vida», así como «proporcionar datos etnográficos a los científicos sociales peruanos y extranjeros». 


\section{Estudiando EL CRistianismo Y LA «RELigión Quechua» EN Ayaviri}

Una década después de la creación de la prelatura, el clero de Ayaviri cuestionó cada vez más la orientación apostólica etnocentrista que había marcado su presencia misionera en el norte de Puno. En un encuentro en 1969, los sacerdotes acordaron nuevas orientaciones pastorales para el año siguiente, que incluían objetivos a corto y largo plazo. Al inicio, decidieron continuar con un enfoque en la evangelización y la provisión de sacramentos en respuesta al sincretismo religioso. Sin embargo, en un futuro previsible, la labor iniciada por el IPA debería dar resultados que habrían de tenerse en cuenta para la reforma de la labor pastoral. ${ }^{15}$ En una circular enviada en 1970, Metzinger criticó más explícitamente la práctica de la evangelización que carecía de reconocimiento y respeto por las creencias andinas. Tal práctica, argumentó, llevó a los feligreses «naturalmente introvertidos» a aislarse, «encubriendo el tesoro de las creencias y tradiciones de sus antepasados». Ante el desafío de descubrir y comprender el «alma, la mentalidad y la cultura» indígena, el prelado exhortó a todos los agentes pastorales a «juntar y acumular los datos que el contacto cotidiano con nuestros feligreses nos proporciona». ${ }^{16}$

La promoción del estudio científico de la religión, que marcó los primeros años de la nueva década, puede inscribirse en trayectorias más amplias de trabajo antropológico en los Andes peruanos. Según Carlos Iván Degregori, el periodo entre 1920 hasta finales de 1960 está marcado por el surgimiento del indigenismo estatal que respondió a los paradigmas de la modernización y la integración. Los antropólogos se encontraban a menudo atrapados en dinámi-

15 AHPA, Caja Consejo Presbiteral, Reunión Sacerdotal del 3 de enero de 1969.

16 AHPA, Caja Provincia Melgar-Historia, Luciano Metzinger, Circular N. 1 a los Sacerdotes, 1970. 
cas conflictivas entre la comprensión y la asimilación, que también se manifestaban en las dos líneas principales de investigación: los estudios folclóricos y la Antropología Aplicada (Degregori 2012: 37-9). Ambas líneas, así como otros proyectos de investigación centrados en el ser humano, también estuvieron presentes en el norte de Puno. El etnólogo estadounidense Harry Tschopik, por ejemplo, al inicio de los años 1940, realizó un trabajo de campo en Chucuito estudiando las prácticas religiosas —denominada «magia»— de la población aymara (2015). Desde una perspectiva diferente, pero que refleja la misma curiosidad por el estilo de vida andino, un equipo de científicos estadounidenses estableció en 1962 un laboratorio en Nuñoa (Melgar) para estudiar la antropología física y la adaptación de la población quechua al ambiente del altiplano (Baker 1976). Las provincias septentrionales, en particular Azángaro, Melgar y Sandia, también acogieron proyectos neoindigenistas de gran envergadura a finales de los años cincuenta y principio de los sesenta, como el Proyecto de Irrigación en Asillo (Dew 1969: 108) y el Programa PunoTambopata dirigido por la Misión Andina de la Organización Internacional del Trabajo (Martínez 1969; Collins 1988). Por muy diversa que haya sido la agenda de investigación antropológica, se apoyó el ideal de una mejor comprensión de las comunidades andinas, así como, en lo que respecta a la Antropología Aplicada, su adaptación o rechazo a los cambios y reformas introducidos por actores estatales y no estatales. En su revisión de los estudios etnológicos de los años setenta, Frank Salomon incluyó los estudios que respondieron al «mandato del Vaticano II de reexaminar las relaciones entre el catolicismo y las religiones no cristianas». Sin embargo, al subsumir estos análisis en el floreciente campo de los estudios andinos, enfatizó que la investigación había sido llevada a cabo a menudo por eclesiásticos que solo aplicaban ideas antropológicas «únicamente de manera instrumental» (Salomon 1982: 100).

Una mirada más atenta a la investigación realizada bajo los auspicios del IPA a principios de los años setenta arroja más luz 
sobre la naturaleza antropológica de estos estudios. Thomas Garr, antropólogo jesuita y autor de Cristianismo y Religión Quechua en la Prelatura de Ayaviri (1972), realizó su estudio de campo en 1971 en tres parroquias diferentes consideradas, por su ubicación, representativas de la prelatura. Dividió su tiempo entre Orurillo, la designada «parroquia piloto» ${ }^{17}$ en el altiplano de Melgar, Coaza, en los valles de Carabaya, y San Juan del Oro, situada a lo largo de la frontera agrícola de Sandia. Con el objetivo de «delinear los aspectos de la religiosidad del campesino», Garr utiliza la introducción de su obra para justificar su metodología de investigación y clarificar su posición frente a sus interlocutores. Precisa, entre otras cosas, que su investigación «no es puramente una etnografía antropológica», ya que, aunque se desarrolla desde un punto antropológico, incluye además aspectos teológicos, así como sugerencias para la práctica pastoral. $\mathrm{Al}$ entrevistar a los habitantes de los tres pueblos, Garr no recurrió a un intérprete y se presentó como sacerdote, lo que le ayudó a acceder a la población local y a no ser considerado únicamente como «el gringo» o, como ocurrió una vez, un «agente de la CIA» (1972: 5-8). Manuel Marzal, referente clave de la antropología de la religión en la América Latina contemporánea, tenía una opinión más ambivalente sobre la posición de los investigadores en sus esfuerzos por entender las creencias y prácticas religiosas andinas. Mientras que, como investigador principal del IPA, animó a los sacerdotes y a los laicos a observar y recoger datos durante su actividad pastoral, también fue cauteloso en cuanto a la falta de preparación metodológica y a la recepción de estos investigadores $a d h o c^{18}$ en las respectivas

17 Según Manuel Marzal, «se entiende por este nombre a aquellas parroquias que se toman en unidad de investigación y experimentación de métodos nuevos, tanto en la pastoral como en la promoción indígena». AHPA, Caja IPA, Instituto de Pastoral Andina, 27 de septiembre de 1968.

18 Probablemente el ejemplo más famoso de estos estudios es el «Proyecto Piloto» en Camacani, Prelatura de Juli (Madden et al. 1976). 
comunidades. ${ }^{19}$ En retrospectiva, argumentando que los agentes pastorales aún se arriesgan a ser percibidos como «herederos de los viejos extirpadores de idolatrías», contradice a Garr al afirmar que la información obtenida por los actores eclesiales y laicos probablemente incluiría «frases ilusivas». Las ofrendas a la Pachamama, ampliamente practicadas por el campesinado del Sur Andino, se reducirían entonces, por ejemplo, a una práctica seguida solamente por "“las comunidades de altura" que representan en este contexto la frontera de la barbarie» (2002: 252). A pesar de estos enfoques diferentes, los diseños de investigación y los objetivos de Marzal y Garr incluían una dimensión pastoral que debía «adaptarse a la gente en su posición existente [...] y además responder a sus necesidades en una cultura venidera radicalmente distinta» (Garr 1972: 3) o, en términos más amplios, manifestar «la importancia de la religión para entender la vida campesina» (Marzal 1988: 40).

En su monografía, Garr basa su análisis de la práctica religiosa en la discusión del contexto social, económico y político de las tres localidades. Un factor particularmente importante para la comprensión de estas parroquias fue el proceso de cambio social en curso, utilizando el término «occidentalización» en lugar de «modernización» («término etnocéntrico») —así como «tradicional» en lugar de «primitivo»— para describir la realidad andina a principios de la década de 1970. Por ejemplo, consideraba que Coaza era un pueblo más aislado y, por tanto, más «tradicional y cerrado» que Orurillo, mientras que San Juan del Oro estaba «en pleno proceso de cambio» debido a la inmigración procedente del altiplano. Sin embargo, la interrelación entre los procesos de cambio social o la llamada occidentalización de los pueblos del norte de Puno y los patrones de creencias religiosas no pareció significativa (Garr 1972: 50-51, 66-67, 208-209). Más bien, su discusión sobre las celebraciones reli-

19 Marzal ofreció algunos «métodos artesanales para la investigación religiosa» a los lectores de Allpanchis en 1972 (Marzal 1972: 185-201). 
giosas, el concepto de Dios, los sacramentos, el matrimonio, el panteón y los expertos religiosos, subraya la existencia simultánea de la «religión tradicional»y el catolicismo como una constelación binaria a menudo mutuamente entrelazada y no separable. De acuerdo con las preguntas existentes sobre la práctica religiosa, desde «¿Puede un campesino cristiano ofrecer un pago a la tierra?» de Marzal (1970) hasta «¿Evangelizados o solamente bautizados?» de Jacques Monast (1972), Garr intenta así comprender el complejo «mundo sagrado» de la población campesina. Al hacerlo, a veces simplificó los patrones de creencia locales — por ejemplo, esbozando una jerarquía religiosa que comprende divinidades católicas y quechuas-, lo que revela las dificultades inherentes a la realización de investigaciones sobre la religiosidad andina, lo cual, como Garr mismo reconoce, es imposible de definir (Garr 1972: 16-17, 183-184).

En la misma línea, Marzal también buscó entender la continuidad y cambios en las creencias y prácticas religiosas a través del prisma de los procesos sociales que habían afectado, y continuaban haciéndolo a un ritmo creciente, al Puno rural y urbano en las últimas décadas. Centrándose en la capital provincial de Ayaviri, considerada una ciudad habitada por «cholos» a mediados de los años setenta, se propuso entender cómo los procesos de modernización impactaron en las imágenes y percepciones de Dios. ${ }^{20}$ Basado en la comprensión de Clifford Geertz de la «religión como sistema cultural» (1973), Marzal afirma que como la religión y la cultura son inseparables, también lo son las creencias en las divinidades cristianas y andinas para aquellos ayavireños que observan ambas prácticas religiosas. En sus palabras, «no es posible dirigirse ni concebir a Dios sino a través del propio lenguaje cultural [...] de acuerdo con la propia herencia cultural y al propio mundo temporal» o, simplemente, a través de las «propias experiencias [humanas]»

20 Su análisis se asemeja a su primer estudio realizado en Urcos, la «parroquia piloto» de la prelatura de Sicuani (Marzal 1971). 
(Marzal 1988: 120; Piedra Valdez 2013: 109). Esta afirmación no solo plantea la cuestión de hasta qué punto la religión puede ser entendida, sino también cómo estos intentos de captar las complejidades inherentes de la práctica religiosa local pueden ser útiles para quienes no comparten las mismas experiencias y el mismo patrimonio cultural. Concluyendo su análisis, Marzal se pregunta: «¿Qué debe hacer la Iglesia institucional con esta "fe en Dios" del pueblo andino?» (1988: 148).

La respuesta de la prelatura tuvo que centrarse en reformular su actividad pastoral, tanto en términos de la posición de los sacerdotes y catequistas como de los mensajes cristianos que difunden. En su análisis sobre el papel de los actores eclesiales —en contraposición a los «expertos religiosos tradicionales»— Garr subraya la dinámica de clase y de poder que juega un papel crucial en la percepción de los agentes pastorales. Estas dinámicas parecían particularmente relevantes para el papel del sacerdote, independientemente de que fuera peruano, como fue el caso en Orurillo, o francés, en Coaza y San Juan del Oro:

[...] el sacerdote en el campo pertenece a una clase social inalcanzable para el campesino. Puede ser que el mismo sacerdote sea de la misma región que la gente, pero una vez que se ha hecho sacerdote, según el parecer de la gente, se ha separado de ese mundo vulgar. El párroco puede hacer muchos esfuerzos para mostrarse abierto y comprensivo de los problemas de la gente de toda clase social y puede tratar de romper las fronteras de estas clases en su trato con la gente, pero siempre va a ser «diferente» y «forastero». [...] Según los mismos campesinos, una identificación total del sacerdote con ellos sería una contradicción. ${ }^{21}$

Las percepciones de los catequistas eran muy parecidas a las de los sacerdotes, aunque en teoría no hay prestigio ni poder vinculado a su oficio religioso. Sin embargo, como señala Garr, a menudo ocurre lo contrario. Los que tienen prestigio dentro de una 
comunidad tienen más probabilidades de ser elegidos catequistas, y los catequistas principales tanto en Coaza como en Orurillo tienden a abusar de su posición para obtener beneficios económicos e influencia política, arriesgándose así a convertirse en los «nuevos "gamonales" religiosos» (Garr 1972: 167-168). Para confrontar y cambiar el papel y las percepciones de los agentes pastorales, Garr subraya la necesidad de fomentar una «Iglesia local» que ya no dependa de «padrecitos» extranjeros, todavía considerados miembros del poder dominante, después de siglos de opresión a través de la «estructura blanca» del catolicismo. Además propone reforzar la autoridad, la autonomía y la educación de los catequistas, ya que son los intermediarios con los que los campesinos pueden identificarse fácilmente (Garr 1972: 218-219). En otras palabras, el antropólogo jesuita reconoce el importante papel que los catequistas jugaron desde la década de 1940 (Zulueta 1967), pero subraya la necesidad de una mayor representación local en la Iglesia, que fue manejada en gran parte por extranjeros. Estos últimos tuvieron que esforzarse cada vez más en la colaboración con sus feligreses y trabajar para lograr una presencia eclesial que constituyera «la expresión legítima de la herencia religiosa local», en lugar de reproducir un modelo occidental de ser Iglesia (Garr 1972: 218).

Más allá de reformas personales, tanto Garr como Marzal sugirieron cambios en el contenido del trabajo pastoral que reflejan la realidad religiosa de los Andes del Sur. Aunque no se refieran explícitamente al concepto de «inculturación» (Piedra Valdez 2013: 49-50; Crollius 1978) desarrollado después del Vaticano II, pero que solo ganó popularidad en las décadas siguientes (Irarrázaval et al. 1988; Judd 1990; Irarrázaval 2000), sus escritos promueven una comprensión de la Iglesia local como una institución adaptada a su entorno sociocultural y, por lo tanto, distinto de la llamada Iglesia universal. Según Piedra Valdez, «la inculturación significa transmitir el mensaje en el lenguaje de los otros», enfatizando así el valor de la práctica de la comunicación para abordar y responder a la pluralidad 
de expresiones religiosas en el cristianismo (2013: 50). Garr, por ejemplo, enfatizó la necesidad de nuevos sermones que respondan a la mentalidad local, para que «ellos mismos puedan conceptualizar y así poder reflexionar acerca de su propia experiencia íntima de revelación». De esta manera, si es posible en quechua, los campesinos pueden desarrollar su propia imagen de Jesús como una persona que habla a la gente, cambiando las percepciones «de una religión de miedo a una religión de atracción» (Garr 1972: 216-217). Las directrices más explícitas incluyen la sugerencia de establecer comunidades eclesiales de base, cambiar los procedimientos en las fiestas religiosas así como la aplicación de los siete sacramentos, y ponen en tela de juicio las prácticas de evangelización anteriores, en línea con una nueva valorización de la cultura local. Sin embargo, al mismo tiempo reconoce también las dificultades para reformar la centenaria posicionalidad y la relación entre el párroco y sus feligreses (Garr 1972: 222, 227-229). En el mismo sentido, Marzal subraya que la Iglesia debe tratar de acompañar a sus feligreses en los procesos de modernización y reforma política y ayudarles a descubrir «nuevas formas de expresión de su fe», sin olvidar que «todas las culturas tienen una facilidad y una dificultad muy parecidas para expresar el misterio de Dios» (Marzal 1988: 149-150).

En contraste con estos dos estudios auspiciados por el IPA, Jean Berthelot ofrece un testimonio más conflictivo basado en su experiencia personal en la Prelatura de Ayaviri. Después de seis años como párroco en Coaza (1962-1968), Berthelot se casó con Chantal Grégoire, que dirigía el dispensario de salud en el mismo distrito, y dejó Puno. En 1972 escribe una carta a Luis Dalle solicitando otras fuentes de interés, en particular los estudios realizados por el IPA, que puede utilizar para su investigación en la École Pratique des Hautes Études, una universidad de París. ${ }^{22}$ Su tesis Religión, Poder y Desarrollo en la Sierra de Carabaya, al igual que los estudios realizados por Garr

22 AHPA, Caja Párrocos Anteriores, Jean Berthelot, carta a Luis Dalle, 11 de enero de 1972. 
y Marzal, examina la región en la que trabajó anteriormente desde la perspectiva de la sociología de la religión y la antropología cultural. Sin embargo, más que en un trabajo de campo a corto plazo, su análisis se basa en la documentación recopilada durante su tiempo como misionero. El trabajo de Berthelot en la parroquia de las tierras altas marcó significativamente la vida religiosa y el paisaje arquitectónico de Coaza durante casi una década. Como señala el Álbum de Oro en 1970, entre los «edificios dignos de consideración» en el pueblo de aproximadamente quinientos habitantes estaban el dispensario de salud, el jardín de infancia y la nueva iglesia, «toda obra de extranjeros» (Dueñas Tovar 1970: 48). A pesar de su compromiso con su parroquia y de la labor social realizada junto a su futura esposa, Berthelot también criticó el estado de la práctica pastoral en la prelatura. Metzinger señaló, por ejemplo, que Berthelot, antes de su partida, lamentaba la falta de aplicación práctica de las directivas del Vaticano II y apoyaba la idea de reclutar sacerdotes indígenas casados. ${ }^{23}$ Esta actitud provocó diferentes reacciones de sus feligreses, criticando o aplaudiendo respectivamente su trabajo como misionero. En una carta al obispo en 1966, por ejemplo, las «autoridades y el pueblo católico de Coaza» denuncian el trabajo de Berthelot por su comportamiento hacia algunos feligreses, acusándolo de querer desaparecer la fe católica, o a través de sus insultos en quechua contra las autoridades elegidas, de «perturbar el espíritu de la masa campesina». ${ }^{24}$ Un año más tarde, sin embargo, los «humildes feligreses» del mismo distrito enviaron una carta al obispo solicitando una prolongación de la estancia de Berthelot y Grégoire, a quienes agradecen por la realización de «obras de trascendental importancia» para la comunidad. ${ }^{25}$

23 AHPA, Caja Párrocos Anteriores, Luciano Metzinger, carta a C. Moller, Subsecretario de la Congregación para la Doctrina de la Fe, 17 de agosto de 1968.

24 AHPA, Caja Coaza, copia del Memorial, 08 de agosto de 1966.

25 AHPA, Caja Coaza, carta a Luciano Metzinger, 20 de julio de 1967. 
Esta postura crítica relativa al gobierno eclesial y el trabajo pastoral también se manifiesta en su análisis de la imbricación de la religión y el poder en Carabaya. En su tesis Berthelot examina la demografía regional, la agricultura, la clase y etnicidad, así como la familia y la educación en el contexto de las tierras altas del norte de Puno. Su análisis de la religión, de resonancia con su artículo escrito para Parole et Mission (1968), revela un conocimiento detallado de la práctica religiosa andina aunque, como admitió en correspondencia anterior, nunca asistió a una ofrenda a la Pachamama. ${ }^{26}$ Sin embargo, enfatiza la dificultad de observar y explicar lo que él llama la «religión india», incluyendo los mitos y la magia, ya que se practica clandestinamente y no puede ser reducida a, o entendida por, el pensamiento occidental (Berthelot 1972: 255, 258). Berthelot critica, por lo tanto, la calificación de las creencias como sincretismo, ya que, refiriéndose a Roger Bastide, el término «sincrético» resume y disimula «una serie de fenómenos o procesos que son extremadamente diferentes» entre sí (2001: 237). Discute en detalle la complejidad de las creencias locales en las que los santos, fiestas y rituales cristianos han sido adoptados y adaptados a la religión andina, de modo que el campesino indígena «no cambia de religión cuando pasa de ofrenda a la Pachamama a la misa [católica]». Más bien, Berthelot considera que la población campesina mantiene una religión que, a pesar de su proceso de adopción de significantes católicos, sigue siendo «profundamente india» (1972: 307-308).

La dicotomía entre «indio» y «occidental» - u «opresión y dominación — también marca las perspectivas analíticas de Berthelot sobre el papel de los agentes religiosos en Coaza. Al igual que Garr, denuncia el privilegio de los sacerdotes, a los que se acercan los feligreses campesinos con la misma actitud que un mestizo, «extremadamente respetuoso y humilde», reflejando «un sentimiento

26 AHPA, Caja Párrocos Anteriores, Jean Berthelot, carta a Luis Dalle, 11 de enero de 1972 . 
de inferioridad desde hace mucho tiempo interiorizado frente al misti». El sacerdote es considerado un miembro de la clase alta, en contraste con la práctica religiosa andina «condenada por el catolicismo al secreto»y que generalmente se practicaba por la noche. Por lo tanto, no es de extrañar para Berthelot que los campesinos de Coaza renuncien a «ocupar los pocos bancos de la iglesia o capilla» ya que se considera «el lugar del mestizo» (1972: 276-277, 314). Debido a la asociación intrínseca entre religión católica y el estatus social, muchos catequistas consideraban su relación con el sacerdote como una fuente de prestigio y un medio para el beneficio personal. Basándose en el ejemplo de uno de sus catequistas, Berthelot argumenta que la competencia que rodea la posición del catequista refleja aún más la idea de que el catolicismo encarna la «sociedad dominante», un fin de la marginación que muchos catequistas presumiblemente anhelaban (1972: 312).

Desde la misma perspectiva dicotómica, Berthelot también criticó los intentos más recientes de comprender el «alma indígena» y adaptar en consecuencia la práctica pastoral en los Andes meridionales. Tanto Garr como Marzal, en sus respectivos análisis, sugieren respectivamente que es necesario «cristianizar una revelación nativa legítima» o «liberar [la visión religiosa] de todos esos "elementos espurios"», distinguiendo así entre características legítimas de la práctica religiosa andina y aquellas consideradas de poco o ningún valor (1988: 150; 1972: 227). Según Berthelot, la búsqueda de valores cristianos en las prácticas religiosas andinas que terminan decidiendo entre la religión verdadera y falsa resuena con el trabajo de extirpación, y por lo tanto solo consolida aún más las relaciones desiguales de poder forjadas por la religión dominante:

La «verdad», la «legitimidad», la «realidad» de los «verdaderos valores humanos», se determinan en referencia a la axiología establecida por la cultura dominante. Para que, para la Iglesia, evangelizar al indio se traduzca finalmente en imponer una forma de pensar, sentir, actuar, conformarse a la sociedad peruana [...] Hasta el punto que podamos 
preguntarnos hoy — y por mucho tiempo ya — si para el Perú y para la Iglesia andina no es un error nacer, o permanecer, indio. ${ }^{27}$

En otras palabras, Berthelot critica fuertemente las relaciones desiguales de poder, o la «dominación», que existen dentro de los dos sistemas religiosos que han sido institucionalizados «hoy como hace más de cuatro siglos, cuando las civilizaciones occidental y autóctona se encontraron por primera vez» (1972: 313). La aparente colonialidad (Quijano 1992) del catolicismo y su manifestación como religión dominante que margina las creencias andinas, no solo subraya la compleja interacción entre etnicidad, clase y religión en los Andes, sino, según el exsacerdote francés, también cuestiona la legitimidad de la práctica de evangelización a pesar del reciente giro antropológico.

Los estudios destinados a comprender las creencias y prácticas religiosas tuvieron que abordar las limitaciones inherentes de posición de los investigadores o de las metodologías empleadas. Como reconocieron, sus estudios solo podían proporcionar una visión parcial de la comprensión local de la religión y del papel del catolicismo en ella. Ya sea por dificultades lingüísticas o por el diseño de la investigación, Berthelot, Garr y Marzal, por ejemplo, manifestaron poco interés en comprender las aspiraciones y opiniones de los catequistas y laicos, y aún menos de las mujeres indígenas, frente a la reforma pastoral. Sin embargo, las limitaciones también dieron forma a las recomendaciones ofrecidas por Garr y Marzal, ya que sus hallazgos demostraron tener poca aplicabilidad más allá de las sugerencias limitadas para la reforma pastoral. Aunque ambos coincidieron en la necesidad de una inculturación de la fe, no abordaron cómo este proceso exacerbaría, como subrayó Berthelot, la contradicción que podría surgir entre el proclamado respeto a la cultura andina y la evangelización.

27 Berthelot (1972: 276). 
Como se comenta en la última parte de este trabajo, el cual coresponde a la prelatura y su aprendizaje de los resultados de estudios auspiciados por el IPA, la reforma de la práctica y discurso pastoral últimamente dependían de los recursos a disposición para traducir el «giro antropológico» en una nueva práctica misionera. Dado que el éxito de la reorientación apostólica depende en gran medida de los colaboradores religiosos que trabajan en la prelatura, se prestará especial atención a la comprensión de sus implicaciones para el clero.

\section{UNA NUEVA MISIÓN PARA LOS NUEVOS CRISTIANOS}

En la Prelatura de Ayaviri las reformas más significativas de la pastoral coincidieron con un cambio en el gobierno eclesial. Después de que Metzinger asumió su trabajo en la Conferencia Episcopal Peruana a principios de 1971, la prelatura fue administrada ad interim por Edmond Gauthier antes de que el papa Pablo VI nombrara a Luis Dalle, del mismo origen y congregación que su predecesor, como el nuevo prelado de Ayaviri. Antes de la ceremonia de su entronización a finales de diciembre de 1971, Dalle convocó una reunión con el clero, congregaciones religiosas femeninas y laicos para discutir la orientación pastoral de la prelatura en grupos de trabajo separados. Cinco de estos grupos discutieron respectivamente sobre la orientación pastoral, la organización parroquial, los agentes pastorales, los catequistas y los laicos. ${ }^{28}$ Estos debates pusieron de relieve las constantes dificultades para definir los papeles de los religiosos y del personal laico, así como las relaciones con los discípulos religiosos en toda la prelatura. Además, la falta de preparación de los catequistas era objetivo de escrutinio. En lugar de «catequis-

28 AHPA, Caja Consejo Pastoral, Grupo de Trabajo N. 1 «Pastoral de la prelatura»; N. ${ }^{\circ} 2$ «Sistema de Trabajo de Párrocos»; N. ${ }^{\circ} 3$ «Los Agentes de la Pastoral»; N. ${ }^{\circ} 4$ «Los Catequistas». 
tas», término asociado a las prácticas coloniales de extirpación, los agentes laicos debían llamarse «líderes» o «animadores cristianos», de acuerdo con su papel más importante en el proceso de evangelización. Haciéndose eco de las preocupaciones de los estudios antropológicos en curso, así como de los debates celebrados en el IPA, los grupos de trabajo elaboraron algunas principales trayectorias de reforma que afectarían a la prelatura a largo de la década de 1970 y que culminarían siendo parte del Plan Pastoral de 1978. Comentando el papel de Luis Dalle, un artículo publicado por Horizons Blancs subrayaba que el nuevo prelado «manifestó su conocimiento del medio indígena» y expresó su «preocupación por una acción pastoral basada en la realidad [andina]» antes de asumir el liderazgo apostólico (Kratz 1972: 12-13).

Los primeros informes sobre la reorientación pastoral explican las dificultades del proceso de reforma iniciado por el nuevo prelado. En su relato de 1973, basado en una visita extendida a Ayaviri, Fernando Ábalos Murillo, encargado de misiones de los Sagrados Corazones, elogiaba los estudios de antropología religiosa desarrollados sobre la región, algo que no había visto en otras jurisdicciones, ${ }^{29}$ y el papel del clero en la producción de conocimientos sobre la religión andina. Al mismo tiempo, el autor compartió su sorpresa ante la «diferencia o el desfase existente en la prelatura entre la antropología religiosa conocida y la aplicación pastoral de la misma». ${ }^{30}$ Para desarrollar una nueva práctica evangelizadora, la Iglesia no solamente debía poner en práctica más rápidamente las recomendaciones elaboradas por los autores antes mencionados, sino también tener en cuenta los nuevos conocimientos sobre el contexto sociorreligioso de sus discípulos:

29 Para tener una visión más global de la actividad misionera de la congregación, ver Ábalos Murillo (1976).

30 ACSCF, Fernando Ábalos Murillo, carta a los Padres SS.CC. de la Prelatura de Ayaviri, 20 de diciembre de 1973. 
Más que cristianizar (que con frecuencia significar hacer a los demás como a nosotros), se trata de descubrir, o mejor todavía, de ayudar a descubrir las posibilidades del hombre andino, lo positivo, sus valores auténticos, el sentido profundo de sus formas, ritos, etc. y permitir así que el quechua se abra a la fe en Cristo, que él pueda tomar una decisión neta en pro o en contra. ${ }^{31}$

Al discutir el difícil proceso de adaptar la práctica de la fe católica al ambiente andino, el informe promueve un tipo de ideal de evangelización que reafirma la alteridad del cristiano campesino en lugar de socavarla. Haciéndose eco de las ideas de la inculturación, Ábalos Murillo sugiere que «el quechua-cristiano de hoy [...] será capaz de reinventar una liturgia auténticamente cristiana y al mismo tiempo plenamente encarnada en su cultura». ${ }^{32}$ En otras palabras, la «autenticidad» de la fe católica ya no dependía de su obediencia al Vaticano, sino del reflejo de las creencias y valores locales en la expresión religiosa. Como tal, el papel de la Iglesia era ayudar a descubrir, apoyada por datos antropológicos, una nueva forma de ser cristiano para la población andina que, sin embargo, corría el riesgo de proyectar una imagen que comprometiera las identidades andinas y cristianas «auténticas».

La colaboración entre clero y laicos, considerada fundamental para que los últimos asuman su rol de «líderes de evangelización», fue también objeto de críticas por parte de los catequistas rurales en sus encuentros regionales. ${ }^{33}$ En una carta de 1972 elogiaron a los obispos por su conocimiento del entorno sociorreligioso, pero lamentaron la falta de personal femenino regional en el campo. Solo a

31 ACSCF, Fernando Ábalos Murillo, carta a los Padres SS.CC. de la Prelatura de Ayaviri, 20 de diciembre de 1973.

32 ACSCF, Fernando Ábalos Murillo, carta a los Padres SS.CC. de la Prelatura de Ayaviri, 20 de diciembre de 1973.

33 AHSC, Caja Parroquia San Juan del Oro Correspondencia, IRCEA, Informe del Consejo de Dirección, Cusco, 07 al 09 de junio de 1971. 
través de una creciente «colaboración de religiosas y expertos tanto en educación familiar como en artesanías», argumentaban los catequistas, sus esposas, a menudo descuidadas en la nueva agenda apostólica y social de la Iglesia, podrían también ser capacitadas. En cuanto a su trabajo junto a los sacerdotes, los catequistas deploran la persistente heterogeneidad del trabajo pastoral en la región:

Vemos que entre los párrocos hay muchas diferencias: unos visitan bastante las comunidades, otros sólo atienden al pueblo y no se mueven al campo, otros dejan la parroquia para ser maestros, algunos sólo dan los sacramentos, otros hacen también evangelización, varios son mandones y como patrones, otros nos ayudan también. ${ }^{34}$

Basándose en esta observación, los catequistas pidieron que los párrocos «renueven su acción y se pongan de acuerdo en una línea común». ${ }^{35}$ Una declaración posterior de la dirección de la escuela de catequesis regional utiliza un lenguaje más crítico frente al clero, quejándose de que «la barrera idiomática para unos, la supuesta falta de tiempo para muchos, la actitud de superioridad y a veces de desprecio de otros, impiden el diálogo con los campesinos». ${ }^{36}$

Además de la creciente colaboración con los laicos, los ideales de una nueva práctica de evangelización exigían más sacerdotes y mejor coordinación dentro de la prelatura, que carecía crónicamente de personal. Una encuesta sobre el trabajo parroquial en Ayaviri realizada en 1971 puso de relieve los obstáculos a una pastoral de conjunto, destacando «la ausencia del obispo, la mentalidad individualista de los sacerdotes» y «la repartición desigual de los sacer-

34 AOP, 15 Catequistas y Animadores, «Carta de los Catequistas a la Iglesia SurAndina», 19 de agosto de 1972.

35 AOP, 15 Catequistas y Animadores, «Carta de los Catequistas a la Iglesia SurAndina», 19 de agosto de 1972.

36 AOP, Guido Delrán, «Informe del Consejo de Dirección del IRCEA a la Asamblea Episcopal Zonal», Cusco, 24 de agosto de 1972. 
dotes según una pastoral que da la prioridad a la celebración de los sacramentos». ${ }^{37}$ Mientras que Ábalos Murillo sugirió que la escasez de sacerdotes se podría remediar con la integración de los laicos, Luis Dalle enfatizó la necesidad de nuevos sacerdotes que pudieran «penetrar el espíritu animista de nuestro pueblo y presentar el evangelio en esta perspectiva». ${ }^{38} \mathrm{Sin}$ «nuevos» ministerios, en otras palabras, la Iglesia no podría guiar a los «nuevos» cristianos quechuas. A finales de 1973, la prelatura contaba con diecinueve sacerdotes para atender a los aproximadamente ciento cincuenta mil discípulos de las tres provincias. Sin embargo, no era la cantidad de sacerdotes presentes en la prelatura lo que más importaba, sino su capacidad para aceptar y adaptarse al ambiente de trabajo de los Andes del Sur. En una carta al Superior de la congregación, Dalle solicitaba «personal adaptado» para el trabajo en la prelatura, «jóvenes y físicamente fuertes» en lugar de los de edad avanzada o los que tienen «dificultades para adaptarse culturalmente». ${ }^{39}$

La falta de personal cualificado, sin embargo, afectó a toda la congregación y ya había sido objeto de escrutinio. Un informe de 1970 sobre el personal religioso de los Sagrados Corazones, por ejemplo, subrayaba que la entonces cuasi provincia carecía de sacerdotes jóvenes, pero también llamaba la atención sobre la particularidad de la situación en Ayaviri. «Los sacerdotes de la prelatura», señala el informe, «tienen la impresión de estar aislados» y consideran que los «sacerdotes de la costa» tienen poco interés en el trabajo apostólico en los Andes. ${ }^{40} \mathrm{Al}$ igual que los funcionarios públicos

37 AHPA, Caja Ayaviri, Encuesta Preparatoria a la Asamblea de los Obispos, enero de 1972.

38 AHPA, Caja Congregación SS.CC., Luis Dalle, carta al Superior de la Congregación, 28 de septiembre de 1973.

39 AHPA, Caja Congregación SS.CC., Luis Dalle, carta al Superior de la Congregación, 28 de septiembre de 1973.

40 AHPA, Caja Cong. SS.CC. Lima, Quasi-Provincia SS.CC. Perú, Informe al Capítulo General de 1970, agosto de 1970. 
- para quienes el despliegue a Puno a menudo equivalía a un castigo-, muchos sacerdotes temían las difíciles condiciones de trabajo de la misión en las tierras altas. La ausencia de intercambios y el sentimiento de aislamiento pesaban cada vez más en las relaciones entre Ayaviri y la congregación en La Recoleta. Expresando su descontento por la falta de apoyo, Dalle criticó la actitud del clero limeño que, según su interpretación, secretamente desea que los «indios que se niegan a aceptar el estilo de vida occidental» desaparezcan. ${ }^{41}$

Aunque el contraste entre el apostolado en Lima y en Ayaviri probablemente exageró las dicotomías actuales que oponen la costa y la sierra, es revelador entender cómo el ambiente marcado por la alteridad cultural y las dificultades socioeconómicas continuaron definiendo la experiencia de la misión en Puno. A pesar de la realidad heterogénea del sacerdocio en Ayaviri, la reorientación apostólica exigía un tipo específico de misionero que se adhiriera a las nuevas normas de la práctica evangelizadora. El misionero ideal no solo era capaz física y mentalmente, sino que renunciaba voluntariamente a ciertas comodidades por el bien de su apostolado. Para la parroquia de San Juan del Oro, por ejemplo, el sacerdote residente propuso enviar a un «sacerdote joven [...] dispuesto a vivir una vida de campesino, completamente despojado del poder», que pase la mayor parte del tiempo junto a sus feligreses, reclute catequistas con éxito $\mathrm{y}$, «obviamente, debe hablar quechua o aymara, o mejor, ambos idiomas». ${ }^{42}$ En línea con las recomendaciones elaboradas por Garr y Marzal, o con las enseñanzas recibidas en el curso anual del IPA, el clero tenía que demostrar su capacidad de evangelizar respetando y defendiendo la cultura quechua. La complejidad de esta tarea fue bien resumida en una contribución al Boletín Informativo del IPA por

41 AHPA, Caja Cong. SS.CC. Lima, Luis Dalle, carta a Jan Scheepens, 20 de febrero de 1976.

42 ACSCF, Nicolás Castel, «San Juan del Oro», Rapports sur les Missions, 14 de agosto de 1973 . 
el sacerdote dominico francés Juan Hugues, preguntado: «¿Cómo respetar la cultura del sur andino y al mismo tiempo querer cambiar la religión sur andina?». ${ }^{43}$

Más allá de las ambigüedades intrínsecas que subyacen a una nueva práctica de evangelización, el clero, los laicos y laicas también tuvieron que reflexionar sobre los objetivos sociales de sus respectivas misiones en y hacia las provincias de Melgar, Carabaya y Sandia. Según Ábalos Murillo, la Iglesia de Ayaviri parecía haber desarrollado una práctica «pos-cristiana, cuando la realidad humano-socioreligiosa sería más bien pre-cristiana» en vista de la «ignorancia religiosa generalizada» y la «inmensa miseria material» de la mayoría de los habitantes. ${ }^{44}$ En su explicación de estas discrepancias, Ábalos Murillo cuestionó la reorientación apostólica de la Iglesia en su respuesta al contexto religioso y socioeconómico:

¿La Iglesia de Ayaviri contribuye de hecho al enorme deber del desarrollo de ese «hombre nuevo», consciente de su dignidad humana, de sus derechos a un pleno desarrollo personal, a un justo puesto en la comunidad humana, es decir, de crear este «otro indio», impelido por una nueva necesidad que al mismo tiempo lo haga libre? ${ }^{45}$

Reflejando el discurso sociopolítico y religioso contemporáneo sobre la creación de un «hombre nuevo» forjado, entre otros, por el gobierno de Velasco Alvarado, el autor enfatiza la necesidad de repensar cómo la evangelización puede contribuir a la liberación y, en última instancia, a la salvación de los hombres y mujeres de los Andes. Para cambiar las estructuras de injusticia y marginación, la Iglesia tuvo que transformar primero a sus discípulos, como «exigi-

43 AHPA, Caja IPA, Juan Hugues, «Respetar la cultura: ¿un problema para la Iglesia?», Boletín Informativo IPA, núm. 19, noviembre de 1972.

44 ACSCF, Fernando Ábalos Murillo, carta a los Padres SS.CC. de la Prelatura de Ayaviri, 20 de diciembre de 1973.

45 ACSCF, Fernando Ábalos Murillo, carta a los Padres SS.CC. de la Prelatura de Ayaviri, 20 de diciembre de 1973. 
da por el evangelio». ${ }^{46}$ La responsabilidad de la Iglesia en el desarrollo o creación de este nuevo, «otro indio», revela las ambigüedades inherentes a las reformas de la práctica misionera en Ayaviri, ya que implica tanto un cambio social hacia un «hombre nuevo» cristiano como un intento de mantener una identidad y una religión andina distinta. En las conclusiones de su informe, Ábalos Murillo se pregunta con razón: «¿Se podrá tener un hombre peruano sur-andino moderno, sin ser necesariamente occidentalizado, es decir, sin tener que renunciar a su propio modo de ser, de pensar, de vivir, etc.?». ${ }^{47}$

\section{ConClusión}

En los primeros años de la década de 1970, el celo misionero de la Iglesia católica se puso cada vez más en tela de juicio. El misionero contemporáneo fue sometido a escrutinio y cuestionado en su papel como agente de cambio religioso, en sus convicciones religiosas y motivos ulteriores. Un editorial de Horizons Blancs de 1972 afirmaba que «durante varios años, las misiones han sido atacadas desde todos los lados» y que en estos «tiempos de prueba» los misioneros encuentran su futuro amenazado, sus motivos cuestionados y «las iglesias locales a veces perciben su presencia como una carga». La actividad misionera católica se dirigió hacia un impasse ético, en el que se cuestionaba la legitimidad misma de la presencia del personal religioso extranjero. Dicho de otra manera, citando una pregunta impresa en el mismo editorial: «iLos misioneros, con su presencia y sus acciones, no mantienen un neocolonialismo eclesiástico?» (Pryen 1972: 77).

46 ACSCF, Fernando Ábalos Murillo, carta a los Padres SS.CC. de la Prelatura de Ayaviri, 20 de diciembre de 1973.

47 ACSCF, Fernando Ábalos Murillo, carta a los Padres SS.CC. de la Prelatura de Ayaviri, 20 de diciembre de 1973. 
Este artículo examina cómo la Iglesia en el Sur Andino, y la prelatura de Ayaviri en particular, experimentó un período de transformación significativa de la comprensión y la práctica de la misión a principios de la década de 1970. Así como el gobierno militar intentó incorporar la población campesina en un nuevo proyecto de «revolución», la Iglesia católica buscó renegociar su relación con sus discípulos indígenas y promover su agencia dentro de una nueva Iglesia andina. En respuesta a los diversos foros y debates organizados en todo el subcontinente sobre la contribución antropológica a la actividad misionera, la práctica de la evangelización debía ser reformada de acuerdo con una nueva comprensión científica de los misionados. Marzal y Garr tenían la tarea de arrojar una nueva luz sobre las «almas misteriosas» de los Andes, los que según la narrativa pos-Medellín — habían sido ignorados, malinterpretados o maltratados por la Iglesia católica durante más de cuatro siglos. Una nueva comprensión de la religiosidad andina resultó útil para comprender el papel que desempeñaba la Iglesia católica en las prácticas y los patrones de creencias, y constituyó un intento importante de abordar y cuestionar el modus operandi del clero católico. Como lo evidenció Berthelot, las discusiones sobre la reforma de la orientación apostólica y de la práctica de la evangelización, sin embargo, también trajeron a primer plano nuevas preguntas sobre las imbricaciones de la cultura, la identidad y la colonialidad de la presencia católica en Puno.

Los debates en torno a los usos y abusos de la antropología en la actividad misionera, ejemplificados por las declaraciones de Barbados y Asunción, ${ }^{48}$ revelan, en efecto, cuán polémicos fueron la realización de los estudios científicos y su aplicación posterior

48 «Declaration of Barbados: For the Liberation of the Indians», International Review of Mission 62, núm. 247 (1 de julio de 1973): 268-274; «Asunción Statement: The Church and Its Mission Among the Indians of Latin America», International Review of Mission 62, núm. 247 (1 de julio de 1973): 275-277. 
en el trabajo pastoral. Luis González, director del Centro Nacional de Pastoral Indigenista de México, argumentó que los actores científicos, estatales y religiosos que trabajan entre las comunidades indígenas tienen que dejar de «inventarlo [al indígena] para mantener o ampliar sus áreas de opresión», sino más bien «descubrirlo» (1973: 284). Su llamado por un «indigenismo indio» reflejaba las convicciones científicas de los antropólogos que trabajaban para el IPA: se trataba de levantar un misterio, crear conocimiento y producir una nueva comprensión de la religión andina. Al mismo tiempo, su «descubrimiento» estaba intrínsecamente ligado al proceso de reforma pastoral que, a su vez, inventó a un hombre nuevo o - en términos religiosos - a un cristiano quechua, como objetivo de la nueva práctica evangelizadora. En otras palabras, proyectaron una nueva identidad cristiana para la población andina que reflejaba perspectivas antropológico-teológicas y, por lo tanto, corría el riesgo de ignorar las aspiraciones y la agencia de los discípulos quechuas en el proceso de reforma pastoral. Como muchos comentaristas contemporáneos reconocieron, esta proyección planteaba nuevos interrogantes con respecto a la compleja interacción entre religión y cultura, o la dinámica de aculturación e inculturación.

Un aspecto importante de este debate, abordado en la última parte del artículo, fue la cuestión de quién debía trabajar por una evangelización liberadora. A principios de la década de 1970, las misiones en toda América Latina dependían más que nunca de las congregaciones religiosas occidentales y de los sacerdotes Fidei Donum. Según el historiador Hans-Jürgen Prien, la Iglesia latinoamericana se vio afectada por una crisis estructural hacia finales de la llamada «cruzada del siglo XX» (Costello 1979). Una expresión particularmente importante de esta crisis fue la falta de vocación autóctona, unida a la crítica de la presencia significativa del clero extranjero (Prien 1985: 1027). Al mismo tiempo, los esfuerzos para revertir la tendencia y aumentar la vocación local en los Andes meridionales apenas tuvieron éxito. Una iniciativa lanzada por la prelatura de Juli 
para promover a los catequistas casados, y la falta de apoyo recibida por el Vaticano, puede servir como un ejemplo ilustrativo. En su carta al prelado Edward Fedders, la Nunciatura Apostólica de Perú argumentaba en 1972 que «entre miles de catequistas de Bolivia, Ecuador y Perú, apenas veinte tendrán una instrucción elemental europea», por lo que no eran aptos para el ministerio. Criticando esta objeción al celibato opcional del clero local, varios catequistas deploraron el uso del término «indio» y, más ampliamente, la falta de conocimiento de la realidad de la Iglesia católica en los Andes demostrada por la Nunciatura. ${ }^{49}$ Más allá de alimentar la crisis estructural en términos de personal religioso, la respuesta del Nuncio reveló también la creciente ruptura entre la progresiva orientación apostólica de ciertas jurisdicciones eclesiales y el universalismo católico, como a menudo defendía la Santa Sede, seguía siendo un proyecto eurocéntrico de religión.

Hacia mediados de los años setenta, el «giro antropológico» perdió su impulso y la reforma de la praxis pastoral hacia la inculturación de la fe católica se ralentizó. Según Estenós Loayza y Ugarte Cornejo, «el discurso culturalista para la inculturación en la Iglesia andina perdió fuerza y transcendencia debido a la irrupción de la Teología de la Liberación» y su reclamo por el «cambio de las estructuras sociales» (2009: 37). En el mismo sentido, y en contraste con el continuo énfasis en la inculturación de la Iglesia en las regiones aimaras vecinas (Fitzpatrick-Behrens 2012: 210-11; Orta 2004), González afirma que el predominio de los temas culturales fue víctima de «la urgencia de los problemas estructurales» (1982: 21-22). Una lectura alternativa de los cambios en la orientación apostólica sugiere que estos constituyen una respuesta no solo al creciente predominio de una comprensión clasista de la sociedad que fue fomentada a través de reformas políticas y eclesiales, sino también una cierta desilusión

49 Carta del Nuncio al obispo Fedders del 09.08.1972, Noticias Aliadas, núm. 46, noviembre de 1973. 
relacionada con los ambiciosos objetivos de reformar radicalmente a una institución conservadora y altamente jerárquica como la Iglesia católica. Sin embargo, es importante subrayar que las reformas iniciadas a principios de los años setenta no terminaron con la adopción de la «opción por los pobres», ya que la prelatura, partiendo del análisis generacional realizado por Pamela Camala Banda (2009), no regresó a la «ortodoxia inicial» durante más que tres décadas.

Después de todo, ¿lograron los antropólogos promover mejores misioneros? Dado que la comprensión científica de la religión plantea cuestiones complejas sobre el significado mismo de la misión para la prelatura, subsisten dudas legítimas sobre la recepción de los estudios antropológicos. Mientras que el uso de las ciencias sociales prometía resolver el «misterio» detrás del «alma indígena» y los sistemas de creencias andinos, la creciente producción de conocimientos sobre la población campesina también cuestionaba la esencia de la práctica de la evangelización en términos de sus implicaciones culturales para aquellos que se creían superficialmente católicos. Sin embargo, los debates sobre si podría existir una práctica «quechua cristiana» y una práctica católica «auténtica» en los Andes no iban a encontrar una respuesta definitiva en los primeros años de gobierno eclesial de Luis Dalle. Más bien, el proceso de inculturación, alimentado por estos estudios antropológicos, experimentó un primer impulso a medida que la Iglesia buscaba mejorar su conocimiento, su servicio pastoral y, en última instancia, su afianzamiento dentro de la población campesina de Ayaviri.

\title{
REFERENCIAS
}

\author{
Archivos \\ Archivo Histórico de la Prelatura de Ayaviri (Puno, Perú) (AHPA). \\ Archivo del Obispado de Puno (Perú) (AOP). \\ Archivo Histórico SS.CC. de la Provincia Andina - Zona Perú (AHSC). \\ Archives de la Congrégation des Sacrés-Coeurs (Francia) (ACSCF).
}


FueNTES BibLIOGRÁFicas

Ábalos Murillo, Fernando

1976 Missionnaires en action: activité missionnaire actuelle de la Congrégation. Roma: Pères des Sacrés Coeurs.

BAKer, Paul T.

1976 Man in the Andes: A Multidisciplinary Study of High-Altitude Quechua. Stroudsburg: Dowden Hutchinson and Ross.

BASTIDE, Roger

2001 Le Prochain et le Lointain. París: L'Harmattan.

Berthelot, Jean

1968 «Coaza: Une “Chrétienneté” Quechua». Parole et Mission, núm. 40, pp. 535-551.

1972 Religion, pouvoir et développement dans la sierra de Carabaya (Pérou). París: École Pratique des Hautes Études.

Cabala Banda, Pamela

2009 «Abuelos, padres, hijos y nietos: un análisis generacional de las prácticas sacramentales en Ayaviri». Allpanchis, núms. 73-74, pp. 69-106.

Collins, Jane Lou

1988 Unseasonal Migrations: The Effects of Rural Labor Scarcity in Peru. Princeton: Princeton University Press.

Costello, Gerald M.

1979 Mission to Latin America: The Successes and Failures of a Twentieth Century Crusade. Nueva York: Orbis Books.

Crollius, Ary A. Roest

1978 «What is so new about Inculturation? A Concept and its Implications». Gregorianum, vol. 59, núm. 4, pp. 721-738.

Dalle, Luis

1969 «El Despacho». Allpanchis, vol. 1, núm. 1, pp. 139-154. 
De Recasens, José

1969 «Resumen General y Conclusiones de la Encuesta (Interpretación y Evaluación de los Datos)». En: Departamento de Misiones CELAM (ed.). Antropología y Evangelización. Bogotá: DMC, pp. 65-126.

Degregori, Carlos Iván

2012 No Hay País Más Diverso: Compendio de Antropología Peruana. Lima: Instituto de Estudios Peruanos.

DEw, Edward M.

1969 Politics in the Altiplano: The Dynamics of Change in Rural Peru. Austin: University of Texas Press.

DueÑas Tovar, Benjamín

1970 «Ensayo Monográfico de la Provincia de Carabaya». En: Álbum de Oro, tomo V, pp. 32-57.

Estenós Loayza, Alejandro y Manuel Ugarte Cornejo

2009 «La Iglesia Católica En El Altiplano: Cinco décadas de trabajo pastoral en la Prelatura de Ayaviri (1959-2005)». Allpanchis, núms. 73-74, pp. 15-69.

FitzPATRick-BeHRENS, Susan

2012 The Maryknoll Catholic Mission in Peru, 1943-1989: Transnational Faith and Transformation. Notre Dame: University of Notre Dame Press.

GARR, Thomas M.

1972 Cristianismo y Religión Quechua En La Prelatura de Ayaviri. Cusco: Instituto de Pastoral Andina.

GeErTz, Clifford

1973 The Interpretation of Cultures: Selected Essays. Nueva York: Basic Books.

GonZÁLEZ, José Luis

1982 «Introducción». En: Cecilia Tovar (ed.). Dos Obispos del Sur Andino: Luis Vallejos, Luis Dalle, en Corazón de Su Pueblo. Lima: Centro de Estudios y Publicación. 
GoNZÁLEZ, Luis R.

1969 «Elementos de Antropología útiles para el Misionero». En: Departamento de Misiones CELAM (ed.). Antropología y Evangelización. Bogotá: DMC, pp. 173-180.

1973 «Anthropology and the "Indian Problem"». International Review of Mission, vol. 62, núm. 247, pp. 278-286.

Hugues, Juan

1973 «El IPA y Allpanchis: Presentación». Allpanchis, vol. 7, pp. 3-4.

ILLICH, Ivan

1967 «The Seamy Side of Charity». America Magazine, núm. 100.

IRARRÁZAVAL, Diego

2000 Inculturation: New Dawn of the Church in Latin America. Nueva York: Orbis Books.

IrarRáZaVAL, Diego y Manuel Marzal (et al.)

1988 «Religiosidad Andina». Allpanchis, núms. 31 y 32.

JuDD, Steven

1990 The emergent Andean Church: Inculturation and Liberation in Southern Peru 1968-1986. Ann Arbor: UMI Dissertation Services.

KLAIBER, Jeffrey L.

1992 The Catholic Church in Peru, 1821-1985: A Social History. Washington D.C.: Catholic University of America Press.

KRATZ, Alfred

1972 «Mgr. Luis Dalle succède à Mgr Lucien Metzinger». Horizons Blancs, núm. 50, pp. 12-13.

Madden, Jaime, Pilar Desmond y Bárbara Cavanaugh

1976 Donde Está Tu Pueblo. Lima: Editorial y Librería Salesiana.

MARTínez, Héctor

1969 Las Migraciones Altiplánicas y la Colonización del Tambopata. Lima: Centro de Estudios de Población y Desarrollo. 
MarzaL, Manuel M.

1970 «Es posible una pastoral en la Iglesia Andina?». Boletín Informativo del IPA, núm. 5, pp. 5-7.

1971 El Mundo Religioso de Urcos: Un Estudio de Antropología Religiosa y de Pastoral Campesina de Los Andes. Cusco: Instituto de Pastoral Andina.

1972 «Investigación Socio-Religiosa y Pastoral». Allpanchis, núm. 4, pp. 185-201.

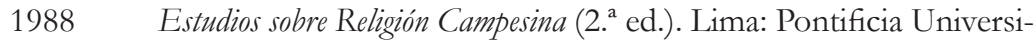
dad Católica del Perú.

2002 Tierra Encantada: Tratado de Antropología Religiosa de América Latina. Madrid: Editorial Trotta.

Monast, Jacques Émile

1972 Los indios aimaraes: ¿evangelizados o solamente bautizados? Buenos Aires: C. Lohlé.

Negre Rigol, Pedro y Franklin Bustillos Gálvez

1970 «Sicuani, 1968: Estudio Socio-Religioso». Sondeos, Cuernavaca, CIDOC, núm. 60.

NIDA, Eugene Albert

1954 Customs and Culture: Anthropology for Christian Missions. Nueva York: Harper and Brothers.

OrTA, Andrew

2004 Catechizing Culture: Missionaries, Aymara, and the "New Evangelization». Nueva York: Columbia University Press.

P. M.

1969 «Un Gringo Chez les Indiens». Parole et Mission, núm. 44, pp. 53-59.

Piedra Valdez, José Leopoldo

2013 La Misión Andina: La Historia de la Palabra Encarnada en los Andes. Lima: Universidad del Pacífico.

Ponce G., Jaime, Julián Rojas, Daniel Roach, E. Cordero y Jaime Mariscal G. 
1970 «Perú: Juli - 1968: Actitudes y Estructuras Sociales». En: CIDOC, Cuaderno núm. 46, Cuernavaca.

PRIEN, Hans-Jürgen

1985 La Historia Del Cristianismo En América Latina. Salamanca: Ediciones Sígueme.

PRYEN, Denis

1972 «Missionnaire aujourd'hui». Horizons Blancs, núm. 53, pp. 77-78.

Quijano, Aníbal

1992 «Colonialidad y Modernidad/Racionalidad». Perú Indígena, vol. 13, núm. 29, pp. 11-20.

Román, José Manuel

1969 «La Realidad de las Misiones en América Latina». En: Departamento de Misiones CELAM (ed.). Antropología y Evangelización. Bogotá: DMC, pp. 191-212.

Romero, Catalina

1982 «Cambios en la relación iglesia-sociedad en el Perú». Debates en Sociologia, núm. 7, pp. 115-141.

SALOMON, Frank

1982 «Andean Ethnology in the 1970s: A Retrospective». Latin American Research Review, vol. 17, núm. 2, pp. 75-128.

SCATENA, Silvia

2007 In Populo Pauperum: La Chiesa Latinoamericana Dal Concilio a Medellin (1962-1968). Bolonia: Societa editrice Il mulino.

Tschopik, Harry Jr.

2015 Magia en Chucuito. Puno: Universidad Nacional del Altiplano.

Young-Hyun, Jo

2005 Sacerdotes y transformación social en el Perú (1968-1975). México: UNAM, Centro Coordinador y Difusor de Estudios Latinoamericanos. 
Zegarra, Pacífico

1969 «Editorial: Cultura Indígena y Pastoral». Boletín Informativo del Instituto de Pastoral Andina, núm. 2, pp. 1-2.

Zulueta, A.

1967 «Los Catequistas de Puno». Separata de Catequética, núm. 8, pp. 1-15.

Fecha de recepción: 29 de julio de 2019.

Fecha de aceptación: 3 de octubre de 2019.

Fecha de publicación: 1 de diciembre de 2020. 